\title{
CORRIGENDUM
}

\section{Therapeutic interventions for spinal cord injury}

Sandrine Thuret, Lawrence D. F. Moon and Fred H. Gage

Nature Rev. Neurosci. 7, 628-643 (2006)

In this article, we referred to Neuraxo Biopharmaceuticals' Cordaneurin therapy as a combination therapy consisting of treatment with a cyclic AMP analogue together with a suppressor of collagen synthesis. Cordaneurin, in fact, consists solely of desferrioxamine as the active pharmaceutical ingredient, in a novel sustained release formulation for local application. Desferrioxamine is approved for human use in iron overload diseases and is an iron chelator that also prevents collagen scarring (S. Hermanns, Neuraxo, personal communication).

An independent group ${ }^{1}$ has confirmed previous work ${ }^{2}$ that a particular iron chelator $\left(2,2^{\prime}\right.$-dipyridyl) reduces collagen IV formation and enhances regeneration of injured brain axons in rats. In addition, a third group ${ }^{3}$ has shown that a lysyl oxidase inhibitor ( $\beta$-aminopropionitrile) enhances the recovery of mice after spinal cord injury.

1. Kawano, H., Li, H. P., Sango, K., Kawamura, K. \& Raisman, G. Inhibition of collagen synthesis overrides the age-related failure of regeneration of nigrostriatal dopaminergic axons. J. Neurosci. Res. 80, 191-202 (2005).

2. Stichel, C. C. et al. Inhibition of collagen IV deposition promotes regeneration of injured CNS axons. Eur. J. Neurosci.

11, 632-646 (1999).

3. Gilad, G. M. \& Gilad, V. H. $\beta$-aminopropionitrile treatment can accelerate recovery of mice after spinal cord injury. Eur. J. Pharmacol. 430, 69-72 (2001). 